\title{
Induction of Mitochondrial Pathways and Endoplasmic Reticulum Stress for Increasing Apoptosis in Ectopic and Orthotopic Neuroblastoma Xenografts
}

\author{
Surajit Karmakar ${ }^{1}$, Subhasree Roy Choudhury ${ }^{1}$, Naren Lal Banik ${ }^{2}$, Swapan Kumar Ray ${ }^{1}$ \\ ${ }^{1}$ Department of Pathology, Microbiology, and Immunology, University of South Carolina School of Medicine, Columbia, USA; \\ ${ }^{2}$ Department of Neurosciences, Medical University of South Carolina, Charleston, USA. \\ Email: swapan.ray@uscmed.sc.edu
}

Received February $26^{\text {th }}, 2011$; revised April 25 $5^{\text {th }}, 2011$; accepted May $4^{\text {th }}, 2011$.

\begin{abstract}
Cancers are characterized by deregulation of multiple signaling pathways and thus monotherapies are hardly effective. Neuroblastoma, which often occurs in adrenal glands, is the most common childhood malignancy. Malignant neuroblastoma resists traditional treatments and further studies are needed for effective therapeutic interventions. We evaluated synergistic efficacy of $N$-(4-hydroxyphenyl) retinamide (4-HPR) and genistein (GST) for induction of apoptosis in human malignant neuroblastoma SH-SY5Y and SK-N-BE2 cells in culture and activation of multiple pathways for increasing apoptosis in ectopic and orthotopic neuroblastoma xenografts in nude mice. Combination of 4-HPR and GST synergistically reduced cell viability, caused subG1 accumulation, increased caspase-3 activity for apoptosis in vitro and reduced tumor growth in vivo. Western blotting indicated that combination therapy down regulated Id 2 to induce differentiation, increased pro-apoptotic Bax and decreased anti-apoptotic Bcl-2 leading to an increase in Bax:Bcl-2 ratio, increased mitochondrial Bax level, caused mitochondrial release of Smac/Diablo, down regulation of the baculovirus inhibitor-of-apoptosis repeat containing (BIRC) proteins such as BIRC-2 and BIRC-3, and activation of calpain and caspase-3 in SH-SY5Y xenografts. Accumulation of apoptosis-inducing-factor (AIF) in cytosol and increase in caspase-4 activation suggested involvement of mitochondrial pathway and endoplasmic reticulum (ER) stress, respectively, for apoptosis in SH-SY5Y xenografts. In situ immunofluorescent labelings of SH-SY5Y and SK-N-BE2 xenograft sections showed overexpression of calpain, caspase-12, and caspase-3, and AIF, suggesting induction of mitochondrial caspase-dependent and caspase-independent pathways for apoptosis. Collectively, synergistic effects of 4-HPR and GST induced mitochondrial pathways and also ER stress for increasing apoptosis in ectopic and orthotopic neuroblastoma xenografts in nude mice.
\end{abstract}

Keywords: Apoptosis, Endoplasmic Reticulum Stress, Genistein, N-(4-Hydroxyphenyl) Retinamide, Neuroblastoma

\section{Introduction}

Retinoid controls a wide range of biological phenomena including differentiation, proliferation, and apoptosis in a variety of cancers in humans [1]. Fenretinide or $\mathrm{N}$-(4-hydroxyphenyl) retinamide (4-HPR), a synthetic retinoid, has shown the most promising broad spectrum anti-cancer efficacy against a variety of in vitro and in vivo animal studies [2], and chemopreventive clinical trials [3]. Notably, 4-HPR showed low toxicity and anti-tumor efficacy even in all-trans retinoic acid (ATRA) or 13-cis retinoic acid (13-CRA) resistant cancer cells; and several in vitro studies reported that dose-dependent anti-tumor efficacy of 4-HPR was mainly due to growth arrest and apoptosis in neuroblastoma [3,4]. Treatment of neuroblastoma patients with high dose of 4-HPR accumulated a plasma 4-HPR concentration that was able to induce apoptosis in neuroblastoma cells [5]. Interestingly, 4-HPR in comparatively low concentrations induces cellular differentiation due to differential expression of a variety of key proteins [6]. Thus, therapeutic potential of low dose of 4-HPR in combination with other therapeutic agent needs to be explored for induction of apoptosis in various cancers including neuroblastoma. 
Development of therapeutic agents from dietary phytochemicals is very promising to fight various human cancers [7]. Genistein (GST), an isoflavonoid primarily derived from soybean, has been reported to inhibit the growth of various cancer cells through alterations in cell signaling pathways, cell cycle, and apoptosis [8]. GST induced apoptosis through endoplasmic reticulum stress and mitochondrial damage in hepatoma Hep3B cells [9] and $\mathrm{Ca}^{2+}$-mediated calpain/caspase-12-dependent apoptosis in breast cancer MCF-7 cells [10]. GST potentially inhibited cellular proliferation in 5 neuroblastoma N2A, JC, SK-N-SH, MSN, and Lan5 cell lines through induction of apoptosis [11]. We previously reported that GST induced activation of calpain and caspases for apoptosis in human neuroblastoma SH-SY5Y cells [12]. These studies suggest that GST could be a strong anti-cancer agent for treating neuroblastoma in vivo as well.

Neuroblastoma is the most frequent extracranial childhood solid tumor derived from sympathetic nervous system mostly affecting adrenal gland and it also usually metastasizes in other body parts including chest, neck, lymph nodes, pelvis, liver, and bone [13,14]. The current therapy for this childhood malignancy comprises surgery, radiation, and chemotherapy; but in most cases of neuroblastoma, therapeutic inefficacy leading to poor clinical outcome may render in excess of $15 \%$ of all pediatric cancer related deaths in children $[15,16]$. Thus, innovative therapeutic approach is urgently warranted for successful treatment of neuroblastoma. Neuroblastoma shows a complex clinical as well as biological heterogeneity [13]. In this investigation, we explored the efficacy of the combination of 4-HPR (for induction of differentiation) and GST (for induction of apoptosis) in human neuroblastoma cells and in ectopic SH-SY5Y and orthotopic SK-N-BE2 xenografts in athymic nude mice. Our data showed that combination of 4-HPR and GST caused more anti-tumor efficacy than monotherapy and they worked synergistically to activate multiple molecular mechanisms for increasing apoptosis in human neuroblastoma cells and in preclinical ectopic SH-SY5Y and orthotopic SK-N-BE2 xenografts in athymic nude mice.

\section{Materials and Methods}

\subsection{Human Neuroblastoma Cell Lines and Culture Conditions}

Human neuroblastoma SH-SY5Y and SK-N-BE2 cell lines were purchased from the American Type Culture Collection (ATCC, Manassas, VA). Cells were grown in $75-\mathrm{cm}^{2}$ flasks containing $10 \mathrm{ml}$ of 1xRPMI 1640 supplemented with $10 \%$ fetal bovine serum (FBS) and $1 \%$ penicillin and $1 \%$ streptomycin in a fully-humidified incubator containing $5 \% \mathrm{CO}_{2}$ at $37^{\circ} \mathrm{C}$. Cell lines were serially passaged following trypsinization using a tryp$\sin$ /EDTA solution.

\subsection{MTT Assay}

The 3(4,5-dimethylthiazol-2-yl)-2,5-diphenyltetrazolium bromide (MTT) assay was used to determine the sensitivities of human neuroblastoma SK-N-BE2 and SH-SY5Y cell lines to 4-HPR $(0.25,0.5$, and $1 \mu \mathrm{M}$ for $72 \mathrm{~h})$ and $\operatorname{GST}(50,100$, and $200 \mu \mathrm{M}$ for $24 \mathrm{~h})$ alone or in combination. Cell viability data were analyzed on the basis of the multiple drug-effect equation (classical isobologram) using the Compusyn software (ComboSyn, Paramus, NJ). The effect (synergistic, additive, or antagonistic) of the combination of drugs (4-HPR and GST) was expressed as the combination index $(\mathrm{CI})$, where $\mathrm{CI}<1$ indicated synergism, $\mathrm{CI}=1$ indicated additive effect, and $\mathrm{CI}>1$ indicated antagonism [17].

\subsection{Flow Cytometric Analysis of Cell Cycle}

Following treatment, cells were collected by trypsinization and centrifugation, then washed with PBS, and fixed with $70 \%$ ethanol. Cells were labeled with propidium iodide (PI) solution $(0.05 \mathrm{mg} / \mathrm{ml} \mathrm{PI}, 2 \mathrm{mg} / \mathrm{ml}$ RNase A, $0.01 \%$ Triton X-100 in PBS) and incubated for $30 \mathrm{~min}$ at room temperature in darkness. Cell cycle (DNA content) was analyzed using an Epics XL-MCL Flow Cytometer (Beckman Coulter, Fullerton, CA) [17].

\subsection{Colorimetric Assay for Determination of Caspase-3 Activity}

Caspase- 3 activity in the lysates of cells or xenografts was measured using the commercially available caspase-3 colorimetric assay kit (Sigma, St. Louis, MO).

\subsection{Annexin V-FITC/PI Staining and Flow Cytometry for Determination of Apoptosis}

Cells from single and combination treatments were harvested and processed with an Annexin V-fluorescein isothiocyanate (FITC)/propidium iodide (PI) staining kit (BD Biosciences, San Jose, CA) for flow cytometric analysis for quantitative determination of apoptosis using an Epics XL-MCL Flow Cytometer (Beckman Coulter, Fullerton, CA). Further, we used $100 \mu \mathrm{M}$ z-DEVD-fmk (a caspase-3-specific inhibitor) to determine the involvement of caspase-3 in apoptosis in cells following combination therapy [17].

\subsection{Human Neuroblastoma Ectopic and Orthotopic Xenografts in Athymic Nude Mice}

Six-week-old female athymic nude (nu/nu) mice were obtained from Charles River Laboratories (Wilmington, MA). All animal studies were conducted following 
guidelines of the NIH Animal Advisory Committee and also approved by our Institutional Animal Care and Use Committee (IACUC). For developing ectopic human neuroblastoma xenografts, SH-SY5Y cells $\left(6 \times 10^{6}\right)$ in $100 \mu \mathrm{l}$ of (1:1) mixture with Matrigel (BD Biosciences, San Jose, CA) were implanted by subcutaneous (s.c.) injection on the flank of each mouse under isoflurane anesthesia condition. Palpable xenografts were developed within 6 - 8 days. Tumors were measured using an external caliper and volume was calculated by the formula: $4 \pi / 3 \times($ length $/ 2) \times(\text { width } / 2)^{2}$. For developing orthotopic human neuroblastoma xenografts, nude mice were anaesthetized using ketamine $(50 \mathrm{mg} / \mathrm{kg})$ and $\mathrm{xy}-$ lazine $(35 \mathrm{mg} / \mathrm{kg})$ intraperitoneally (i.p.). After a midline incision, a total of $6 \times 10^{5}$ SK-N-BE2 neuroblastoma cells in $15 \mu \mathrm{l}$ of 1 xRPMI 1640 were injected in the capsule of the left adrenal gland using a 22 gauge needle attached to a Hamilton syringe. After implantation of cells, abdominal wall and skin were closed with a 5-0 LOOK $^{\circledR}$ suture (Surgical Specialties, Reading, PA) and antiseptic-analgesic ointments were applied and animals were kept in a pathogen-free animal facility [18]. Animals with 3 weeks-old neuroblastoma xenografts were randomly divided into four groups: control (CTL), 4-HPR, GST, and 4-HPR + GST. Animals in control group did not receive any therapy. Each animal in other group received i.p. a daily dose of 4-HPR $(20 \mu \mathrm{g} / \mathrm{kg} / \mathrm{day})$, GST $(2 \mathrm{mg} / \mathrm{kg} / \mathrm{day})$, or $4-\mathrm{HPR}(20 \mu \mathrm{g} / \mathrm{kg} / \mathrm{day})+4 \mathrm{~h}$ later GST ( $2 \mathrm{mg} / \mathrm{kg} /$ day) for 8 days.

\subsection{Histological Examination of Tumor Xenografts}

After completion of treatment schedule, mice were sacrificed, both ectopic and orthotopic neuroblastoma xenografts were surgically collected. After washing with PBS, $\mathrm{pH} 7.4$, tumors were either immediately frozen in liquid nitrogen and strored at $-80^{\circ} \mathrm{C}$ for future use or immediately frozen $\left(-80^{\circ} \mathrm{C}\right)$ in Optima Cutting Temperature media (Fisher Scientific, Suwanee, GA) and $5 \mu \mathrm{m} \mathrm{sec-}$ tions were cut with a cryostat. These sections were stained for routine histological examinations [19].

\subsection{In Situ Immunofluorescent Labeling for Detection of Pro-Apoptotic Protein Expression}

For in situ immunofluorescent labelings, samples were fixed to slides using $95 \%(\mathrm{v} / \mathrm{v})$ ethanol for $10 \mathrm{~min}$ and rinsed twice for $10 \mathrm{~min}$ each in PBS, pH 7.4. Fixation and all subsequent steps were conducted at room temperature. Sections were blocked with $2 \%(\mathrm{v} / \mathrm{v})$ horse and goat sera (Sigma, St. Louis, MO) for $30 \mathrm{~min}$. Samples were probed with (1:100) primary IgG antibody for $1 \mathrm{~h}$ and slides were rinsed twice in PBS, pH 7.4, for 5 min each followed by incubation with (1:75) secondary Texas Red-conjugated anti-rabbit IgG antibody (Vector Laboratories, Burlingame, CA) for $30 \mathrm{~min}$. Slides were then

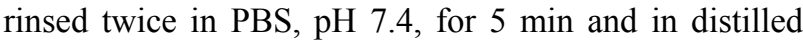
water for $5 \mathrm{~min}$. The slides were immediately mounted with VectaShield (Vector Laboratories) and viewed promptly under a fluorescence microscope at 200x magnification (Olympus, Japan), and digital pictures were taken with Image-Pro Plus software (Media Cybernetics, Silver Spring, MD), as we described recently [20].

\subsection{Combined Terminal dUTP Nick-End Labeling (TUNEL) and Double Immunofluorescent Stainings for Detection of Apoptosis and Upregulation of a Pro-Apoptotic Protein}

Briefly, xenograft tissues were sectioned, fixed in $95 \%$ $(\mathrm{v} / \mathrm{v})$ ethanol for $10 \mathrm{~min}$ and then post-fixed in $4 \%$ methanol-free formaldehyde for $10 \mathrm{~min}$. The sections were saturated with TdT equilibration buffer (Promega, Madison, WI, USA) ( $50 \mu \mathrm{l} / \mathrm{slide})$ for $5 \mathrm{~min}$ and then replaced with TUNEL reaction mixture $(50 \mu \mathrm{l} / \mathrm{slide})$ and were incubated for $1 \mathrm{~h}$ at $37^{\circ} \mathrm{C}$ in an OmniSlide Thermal Cycler (Hypaid, UK). Following the TUNEL reaction, slides were immuno-stained with primary IgG antibody for specific protein and then incubated with flouresceinated secondary antibodies and images were taken [20].

\subsection{Western Blotting and Detection of Specific Protein Bands}

Western blotting was used for analyzing specific proteins [20]. Briefly, total protein samples from tumor tissue were extracted, measured spectrophotometrically and denatured. Samples were loaded onto the SDS-polyacrylamide gradient (4\% - 20\%) gels (Bio-Rad, Hercules, CA), resolved by electrophoresis, and electroblotted to membranes. The blots were incubated with a primary $\operatorname{IgG}$ antibody followed by incubation with an alkaline horseradish peroxidase (HRP)-conjugated secondary IgG antibody. Specific protein bands on the blots were detected by $\mathrm{HRP} / \mathrm{H}_{2} \mathrm{O}_{2}$ catalyzed oxidation of luminol in alkaline condition using enhanced chemiluminescence (ECL) system (GE Healthcare Bio-Sciences, Piscataway, NJ) followed by autoradiography. Autoradiograms were scanned using Photoshop software (Adobe Systems, Seattle, WA), and OD of each band was determined using NIH Image software.

\subsection{Colorimetric Assay for Determination of Caspase-4 Activity}

Caspase-4 activity in tumor lysates was measured using 
the commercially available caspase- 4 activity colorimetric assay kit (BioVision, Mountain View, CA).

\subsection{Statistical Analysis}

Data were analyzed using the StatView software (Abacus Concepts, Berkeley, CA), expressed as arbitrary units \pm standard error of mean (SEM) of separate experiments $(n$ $\geq 3$ ), and compared by one-way analysis of variance (ANOVA) followed by the Fisher post hoc test. A significant difference between control and treatment was indicated by $*(p<0.05)$ or $* *(p<0.001)$.

\section{Results}

\subsection{Changes in Cell Viability}

We used human malignant neuroblastoma SK-N-BE2 and SH-SY5Y cells in cultures to determine the effects of treatments (Figure 1). Changes in cell viability in were determined by the MTT assay (Figure 1(a)). We used 4-HPR or GST alone as monotherapy and also 4-HPR + GST as combination therapy. Notably, 4-HPR $(0.5 \mu \mathrm{M}$ for $72 \mathrm{~h})+\mathrm{GST}(100 \mu \mathrm{M}$ for $24 \mathrm{~h})$ and 4-HPR (1 $\mu \mathrm{M}$ for $72 \mathrm{~h})+\mathrm{GST}(200 \mu \mathrm{M}$ for $24 \mathrm{~h})$ caused most significant decrease in cell viability when compared with CTL and other treatment groups (Figure 1(a)). Data were analyzed to generate the combination index (CI) of the drugs. The effect of 4-HPR + GST was found to produce $\mathrm{CI}<1$ in neuroblastoma SK-N-BE2 $(\mathrm{CI}=0.78)$ and SH-SY5Y $(\mathrm{CI}=0.95)$ cells, indicating synergistic action of the combination of drugs. Finally, 4-HPR $(0.5 \mu \mathrm{M}$ for $72 \mathrm{~h})$, GST $(100 \mu \mathrm{M}$ for $24 \mathrm{~h})$, and 4-HPR $(0.50 \mu \mathrm{M}$ for $72 \mathrm{~h})+\mathrm{GST}(100 \mu \mathrm{M}$ for $24 \mathrm{~h})$ were selected as effective treatments and used in all subsequent cell culture studies.
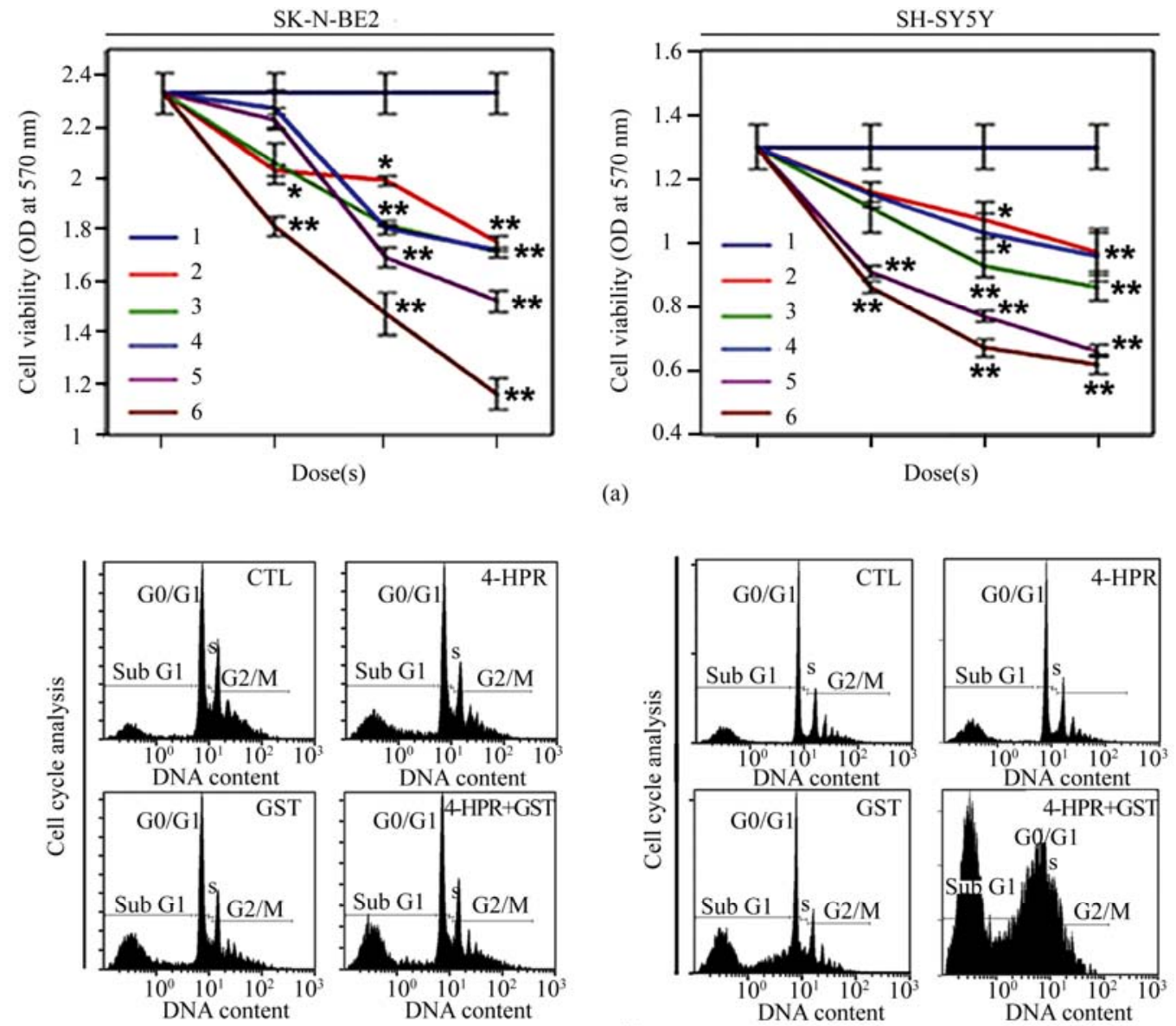

(b)

Figure 1. Effects of treatments on human malignant neuroblastoma SK-N-BE2 and SH-SY5Y cells. (a) Changes in cell viability in neuroblastoma cells as determined by MTT assay. Treatments: 1. control (CTL); 2. 4-HPR (0.25, 0.5, and $1 \mu$ M for 72 h); 3 . GST (50, 100, and $200 \mu \mathrm{M}$ for $24 \mathrm{~h})$; 4. 4-HPR $(0.25 \mu \mathrm{M}$ for $72 \mathrm{~h})+$ GST $(50 \mu \mathrm{M}$ for $24 \mathrm{~h})$; 5. 4-HPR (0.5 $\mu \mathrm{M}$ for $72 \mathrm{~h})+$ GST $(100 \mu \mathrm{M}$ for $24 \mathrm{~h})$; and 6. 4-HPR $(1 \mu \mathrm{M}$ for $72 \mathrm{~h})+$ GST $(200 \mu \mathrm{M}$ for $24 \mathrm{~h})$. Finally, 4-HPR $(0.5 \mu \mathrm{M}$ for $72 \mathrm{~h})+\mathrm{GST}(100 \mu \mathrm{M}$ for $24 \mathrm{~h}$ ) was selected for all other cell culture studies. (b) Cell cycle analysis by flow cytometry in SK-N-BE2 and SH-SY5Y cells. Combination therapy induced apoptotic subG1 accumulations. 


\subsection{Cell Cycle Analysis}

We found treatments (4-HPR, GST, and 4-HPR + GST) significantly increased apoptotic subG1 phase $(10,18$, and 28\%, respectively) in SK-N-BE2 cells (Figure 1(b)). In case of SH-SY5Y cells (Figure 1(b)), 4-HPR treatment showed non-significant change, while GST (35\%) and 4-HPR + GST (51\%) treatments exhibited significant increases in apoptotic subG1 phase, compared with untreated cells (Figure 1(b)).
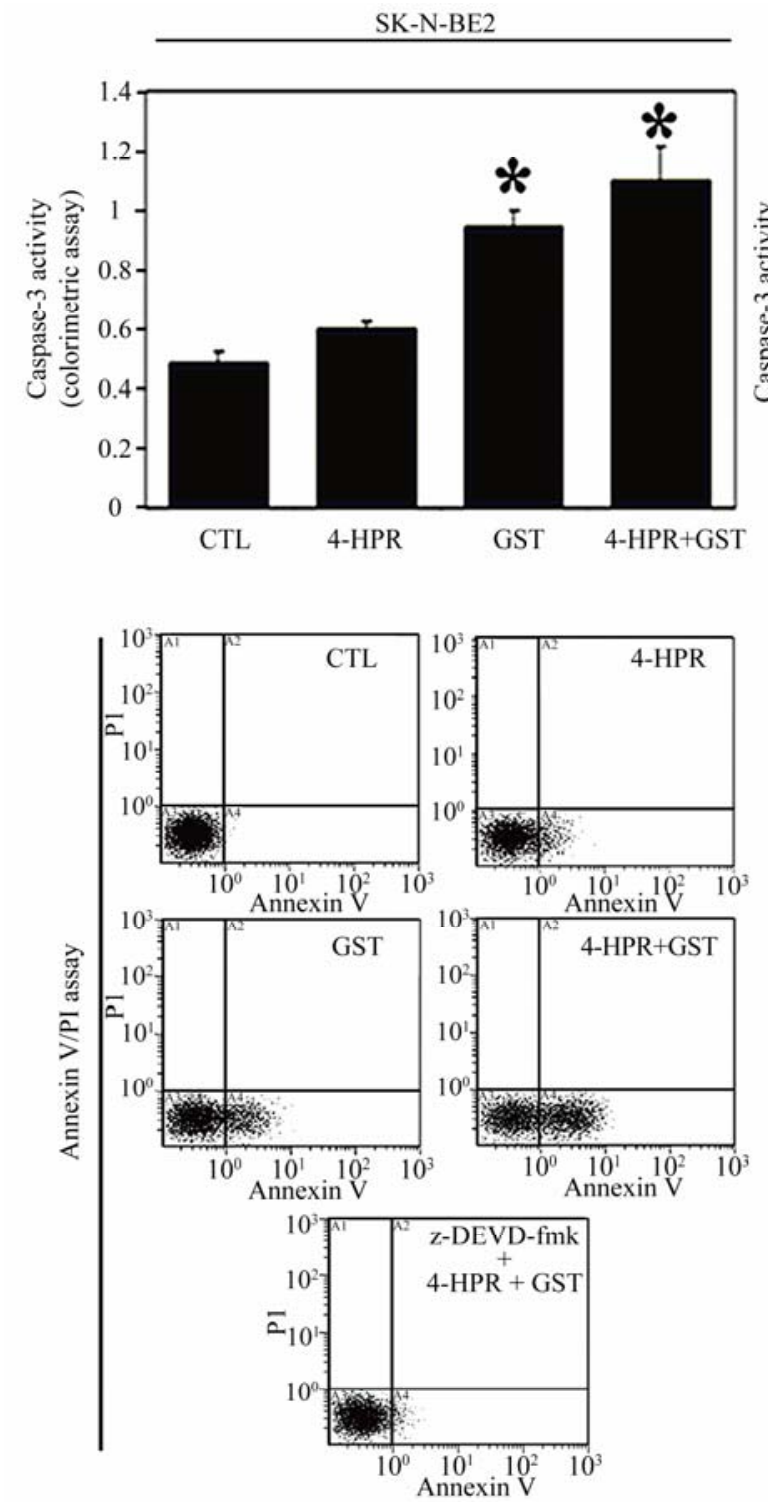

(a)

\subsection{Increase in Caspase- 3 Activity}

We determined the caspase-3 activity in apoptosis and amounts of apoptotic cells following treatments (Figure 2). Increases in caspase- 3 activity in course of apoptosis in both neuroblastoma cell lines were measured by a colorimetric assay (Figure 2(a)). The caspase-3 activity in cell lysate was most significantly found in both cell lines after treatment with 4-HPR + GST, compared with untreated cells (Figure 2(a)).
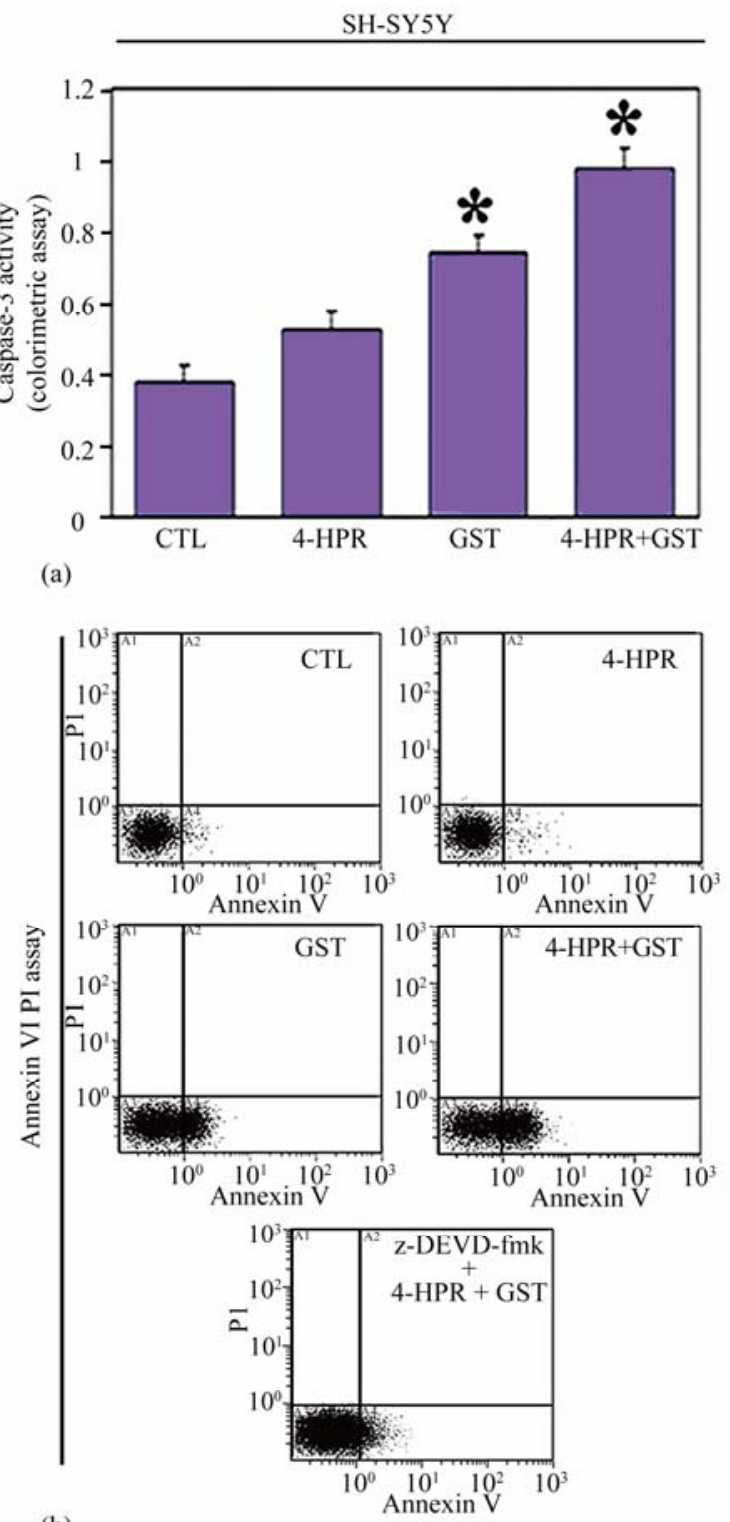

(b)

Figure 2. Increases in caspase-3 activity and apoptotic populations in SK-N-BE2 and SH-SY5Y cells. Treatments: CTL, 4-HPR (0.5 $\mu$ M for $72 \mathrm{~h})$, GST $(100 \mu \mathrm{M}$ for $24 \mathrm{~h})$, and 4-HPR $(0.5 \mu \mathrm{M}$ for $72 \mathrm{~h})+$ GST $(100 \mu \mathrm{M}$ for $24 \mathrm{~h})$. (a) Determination of caspase-3 activity using a colorimetric assay. (b) Annexin V-FITC/PI staining and flow cytometric determination of apoptosis. Treatment with 4-HPR + GST effectively controlled growth of neuroblastoma cells due to increase in caspase-3 activity for apoptosis. 


\subsection{Increase in Apoptosis Was Associated with Upregulation of Caspase-3}

Our Annexin V-FITC/PI staining and flow cytometric studies showed the percentages of Annexin V-positive/ PI-negative populations (early apoptotic) in neuroblastoma SK-N-BE2 (CTL, 2\%; 4-HPR, 8\%; GST, 20\%; and 4-HPR + GST, 32\%) and SH-SY5Y (CTL, 2\%; 4-HPR, 3\%; GST, 32\%; and 4-HPR + GST, 47\%) cells (Figure 2(b)). Pre-treatment with $100 \mu \mathrm{M}$ z-DEVD-fmk (a caspase-3-specific inhibitor) significantly reduced the capability of combination therapy for induction of apoptosis to $5.28 \%$ in SK-N-BE2 cells and to $18.45 \%$ in SH-SY5Y cells, indicating involvement of caspase- 3 in induction of apoptosis in both cell lines (Figure 2(b)).

\subsection{Histological Evaluation of Efficacy of Combination Therapy}

We treated ectopic SH-SY5Y xenografts in nude mice (Figure 3). As seen in the animals (Figure 3(a)), treatments caused tumor regression. Following treatments, the tumors were collected surgically to measure tumor volume (Figure 3(b)). Treatment with 4-HPR + GST caused more regression of SH-SY5Y tumors than either drug alone. Further, we performed hematoxylin and eosin (H\&E) staining of tumor sections and histological examination at 200x magnification under the light microscope (Figure 3(c)), showing maximum cell death after combination therapy.

Similarly, the efficacy of combination therapy was evaluated in orthotopic SK-N-BE2 xenografts in nude mice (Figure 4). Following 4-HPR or GST monotherapy and 4-HPR + GST combination therapy of orthotopic SK-N-BE2 xenografts (Figure 4(a)), tumor sections from each group were subjected to $\mathrm{H} \& \mathrm{E}$ staining followed by histological examination under the light microscope at 200x magnification (Figure 4(b)). In orthotopic xenografts also, combination therapy caused maximum cell death.

Examination of sections of all neuroblastoma ectopic SH-SY5Y xenografts and orthotopic SK-N-BE2 xenografts after $\mathrm{H} \& \mathrm{E}$ staining revealed that untreated tumors maintained characteristic growth of neuroblastoma, 4-HPR alone inhibited tumor cell proliferation and caused neuronal differentiation, GST alone induced apoptosis, and 4-HPR + GST combination therapy dramatically increased the amounts of apoptosis.

\subsection{Combination Therapy down Regulated Id2 and Increased Bax:Bcl-2 Ratio in SH-SY5Y Xenografts}

We performed Western blotting (Figure 5) and found

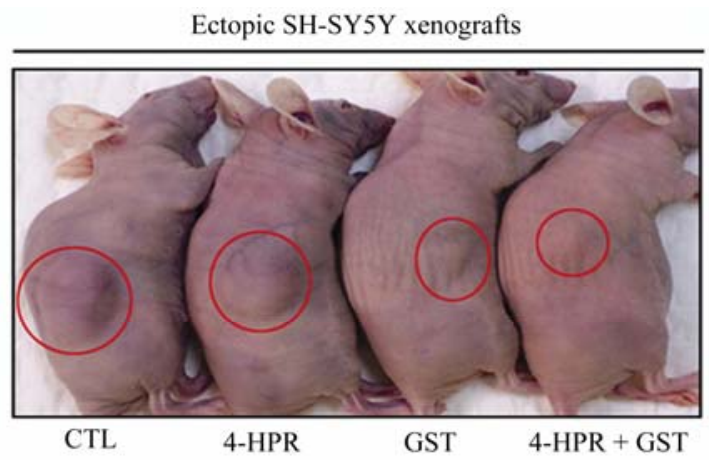

(a)

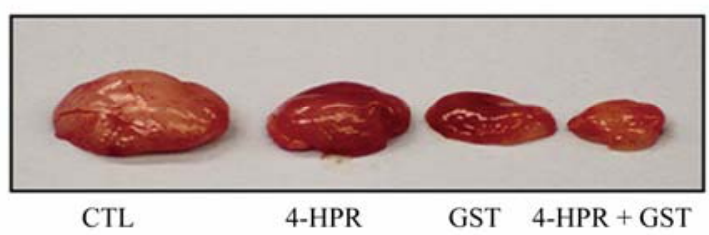

(b)

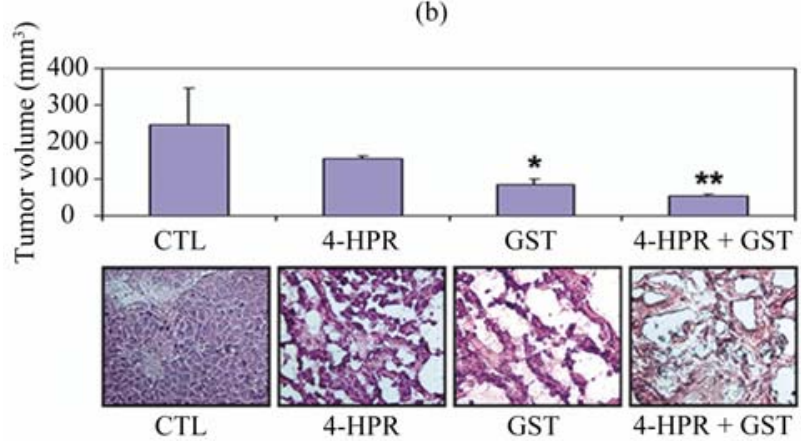

(c)

Figure 3. Efficacy of combination therapy in ectopic SHSY5Y xenografts. (a) Ectopic SH-SY5Y xenografts in nude mice. Treatments (8 days): control (CTL), 4-HPR (20 $\mu \mathrm{g} / \mathrm{kg} / \mathrm{day})$, GST ( $2 \mathrm{mg} / \mathrm{kg} / \mathrm{day})$, and $4-H P R(20 \mu \mathrm{g} / \mathrm{kg} / \mathrm{day})$ plus $4 \mathrm{~h}$ later GST ( $\mathrm{mg} / \mathrm{kg} / \mathrm{day})$. (b) The representative tumors after treatments. (c) Histological features (at 200x magnification) of SH-SY5Y xenografts after treatments.

that treatment with 4-HPR + GST down regulated inhibitor-of-differentiation 2 (Id2), and changed the levels of expression of total Bax and Bcl-2 (Figure 5(a)) resulting in significant increase in the Bax:Bcl-2 ratio, compared with CTL xenograft (Figure 5(b)). The elevation of Bax:Bcl-2 ratio could make cells fully committed to apoptosis due to mitochondrial release of several pro-apoptotic molecules. Further, we isolated the mitochondrial fractions to analyze the change in mitochondrial Bax level and monitored the COX-4 level as mitochondrial internal control (Figure 5(c)). We found that treatment with 4-HPR + GST caused more increase in mitochondrial Bax level in the SH-SY5Y xenografts than either therapy alone (Figure 5(d)). 


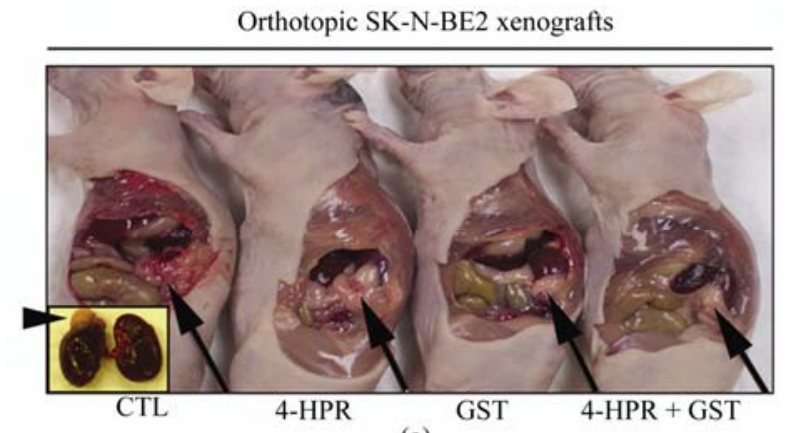

(a)

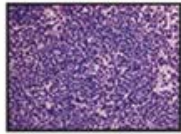

CTL

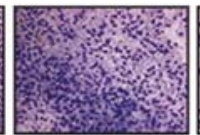

4-HPR

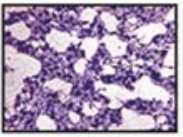

GST

(b)

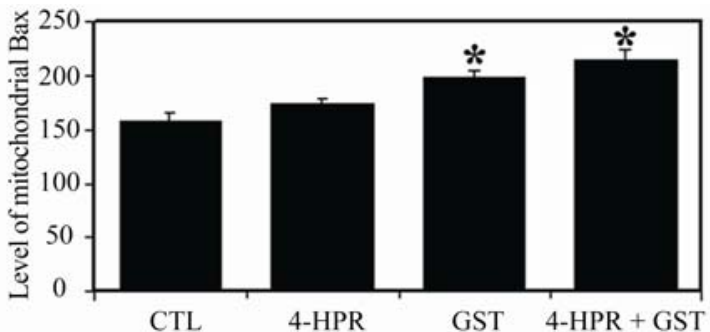

(d)
Figure 5. Western blotting for biochemical feature of differentiation and determination of Bax:Bcl-2 ratio and mitochondrial Bax level in SH-SY5Y xenografts. Treatments (8 days): CTL, 4-HPR (20 $\mu \mathrm{g} / \mathrm{kg} / \mathrm{day})$, GST (2 mg/kg/day), and 4-HPR $(20 \mu \mathrm{g} / \mathrm{kg} / \mathrm{day})+4 \mathrm{~h}$ later GST $(2 \mathrm{mg} / \mathrm{kg} / \mathrm{day})$. (a) Representative Western blots $(n \geq 3)$ to show expression of $42 \mathrm{kDa} \beta$-actin, $16 \mathrm{kDa}$ Id2, 21 and $24 \mathrm{kDa}$ Bax, $26 \mathrm{kDa}$ Bcl-2. (b) Densitometric analysis to show change in the Bax:Bcl-2 ratio. (c) Representative Western blots $(n \geq$ 3) to show expression of $17 \mathrm{kDa} C O X-4,21$ and $24 \mathrm{kDa}$ Bax in mitochondrial fraction. (d) Densitometric analysis to show relative changes in the mitochondrial Bax level following treatments.

\subsection{Combination Therapy Caused Mitochondrial Release of Pro-Apoptotic Molecules and Down Regulation of BIRC Proteins for Activation of Cysteine Proteases in SH-SY5Y Xenografts}

Therapeutic treatment may cause mitochondrial release of pro-apoptotic molecules [21]. We performed Western blotting to examine mitochondrial release of Smac/Diablo and levels of BIRC proteins and cysteine proteases in SH-SY5Y xenografts (Figure 6). Compared with CTL or 4-HPR alone or GST alone, 4-HPR + GST highly induced mitochondrial release of pro-apoptotic protein 25 $\mathrm{kDa}$ Smac/Diablo into the cytosol (Figure 6(a)) and levels of the anti-apoptotic proteins $72 \mathrm{kDa}$ BIRC-2 (cIAP-1), $68 \mathrm{kDa}$ BIRC-3 (cIAP-2) in the cytosol (Figure 6(a)). We also found that combination therapy increased expression of $80 \mathrm{kDa}$ calpain, $20 \mathrm{kDa}$ caspase-3, and mitochondrial $67 \mathrm{kDa}$ apoptosis-inducing factor (AIF) into the cytosol (Figure 6(a)). Further, we used Western blotting and colorimetric assay and found increased caspase- 4 activation and total caspase- 4 activity, respectively, indicating increase in ER stress, for apoptosis in the SH-SY5Y xenografts after treatment with 4-HPR + GST (Figure 6(b)).

\subsection{Combination Therapy Caused Upregulation of Calpain and Caspase-12 for Apoptosis in Ectopic and Orthotopic Neuroblastoma Xenografts}

We performed the single immunofluorescent (SIF) and 


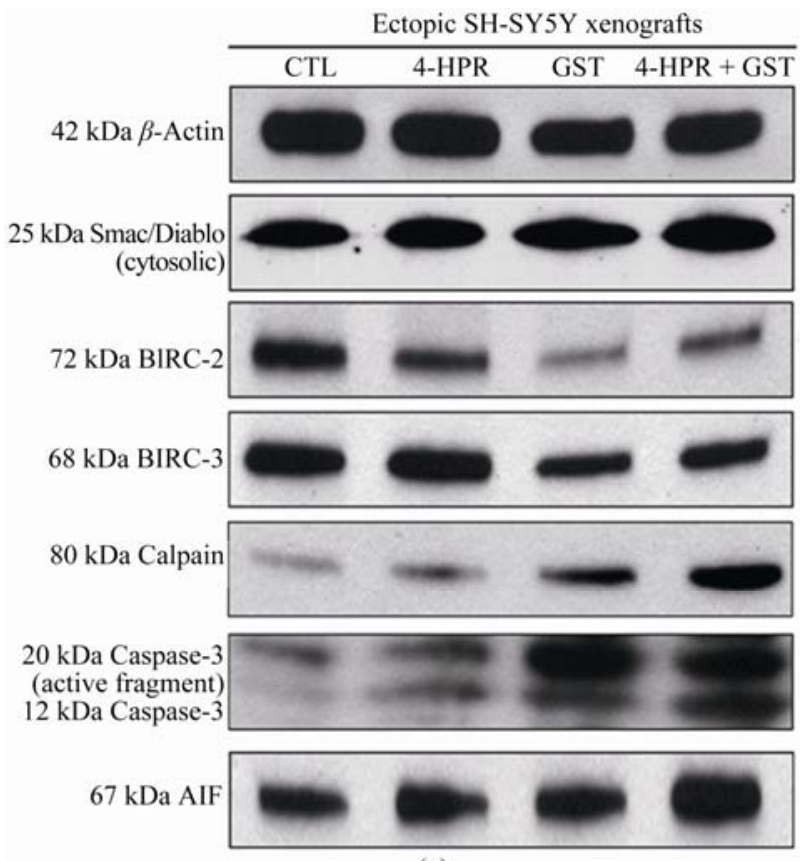

(a)
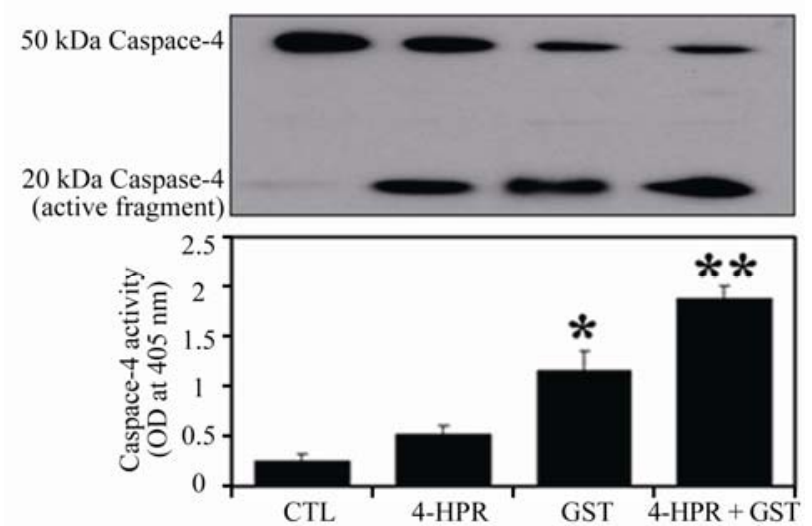

(b)

Figure 6. Activation of caspase-dependent and caspaseindependent pathways for apoptosis in SH-SY5Y xenografts. Treatments (8 days): CTL, 4-HPR (20 $\mu \mathrm{g} / \mathrm{kg} / \mathrm{day})$, GST $(2 \mathrm{mg} / \mathrm{kg} / \mathrm{day})$, and 4-HPR $(20 \mu \mathrm{g} / \mathrm{kg} / \mathrm{day})+4 \mathrm{~h}$ later GST ( $2 \mathrm{mg} / \mathrm{kg} / \mathrm{day})$. (a) Representative Western blots $(n \geq 3)$ to show expression of $42 \mathrm{kDa} \beta$-actin, $25 \mathrm{kDa} \mathrm{Smac} / \mathrm{Diablo}$, 72 kDa BIRC-2, 68 kDa BIRC-3, 80 kDa Calpain, 20 kDa and $12 \mathrm{kDa}$ active caspase-3, and $67 \mathrm{kDa}$ AIF. (b) Western blotting showed active $20 \mathrm{kDa}$ caspase-4 fragment. Bar diagram to show changes in caspase- 4 activity as determined by a colorimetric assay.

double immunofluorescent (DIF) stainings of the xenograft sections after the treatments (Figure 7). The SIF staining showed that compared with CTL or monotherapy, 4-HPR + GST combination therapy very significantly increased expression of calpain and caspase-12 in ectopic SH-SY5Y xenografts (Figure 7(a)) as well as in orthotopic SK-N-BE2 xenografts (Figure 7(b)). Subsequently, the DIF staining showed highly remarkable overexpression of calpain and caspase-12 in association with increase in DNA fragmentation in ectopic SH-SY5Y xenografts (Figure 7(a)) and orthotopic SK-N-BE2 xenografts (Figure 7(b)) following 4-HPR + GST combination therapy.

\subsection{Combination Therapy Induced Activation of Caspase-Dependent and Caspase-Independent Pathways for Apoptosis}

To explore the downstream executioner steps, we examined the caspase- 3 and AIF levels in all treatment groups from both SH-SY5Y and SK-N-BE2 xenografts (Figure 8). Following the SIF staining, we found significant increases in caspase-3 and AIF expression in ectopic SH-SY5Y xenografts (Figure 8(a)) as well as in orthotopic SK-N-BE2 xenografts (Figure 8(b)) due to 4-HPR + GST combination therapy. The DIF staining showed that significant increases in caspase-3 and AIF expressions were associated with DNA fragmentation in both ectopic and orthotopic xenografts following the 4-HPR + GST combination therapy (Figure 8(b)). These studies confirmed the involvement of caspase-dependent pathway along with non-caspase pathway for induction of apoptosis in both ectopic SH-SY5Y and orthotopic SK-N-BE2 xenografts after the 4-HPR + GST combination therapy.

\section{Discussion}

In this investigation, we found that 4-HPR + GST worked synergistically to significantly reduce the viability of neuroblastoma SH-SY5Y cells (N-Myc expression without N-myc gene amplification) and SK-N-BE2 cells (N-Myc overexpression with N-myc gene amplification) [22] and induce caspase-3 activity for apoptosis. Previous studies reported that 4-HPR [3,23] or GST [12] induced apoptosis in a variety of cell lines including neuronblastoma $[4,12]$ with activation of caspase-3. The synergistic efficacy of 4-HPR + GST activated multiple pathways for increasing apoptosis, as suggested by molecular and histological observations, in two preclinical neuroblastoma animal models such as ectopic SH-SY5Y and orthotopic SK-N-BE2 xenografts.

We found that 4-HPR + GST caused down regulation of Id2, a biochemical marker well known to antagonize differentiation [24], indicating induction of molecular mechanism of differentiation in SH-SY5Y xenografts. The increases in Bax:Bcl-2 ratio and translocation of Bax to mitochondria could be the key events for apoptosis in neuroblastoma cells [12,25] and also well correlated 
Ectopic SH-SY5Y xenografts

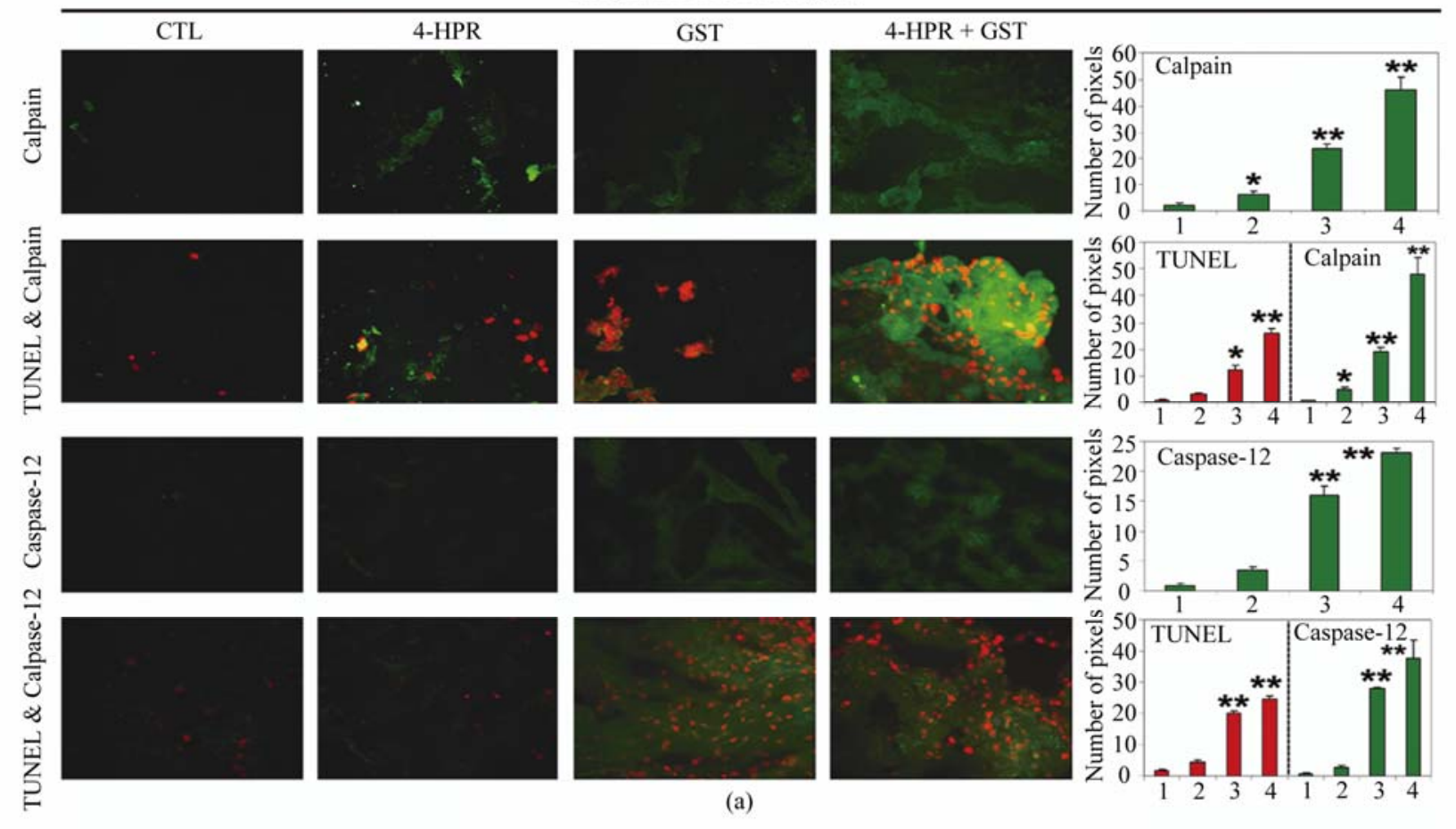

Orthotopic SK-N-BE2 xenografts
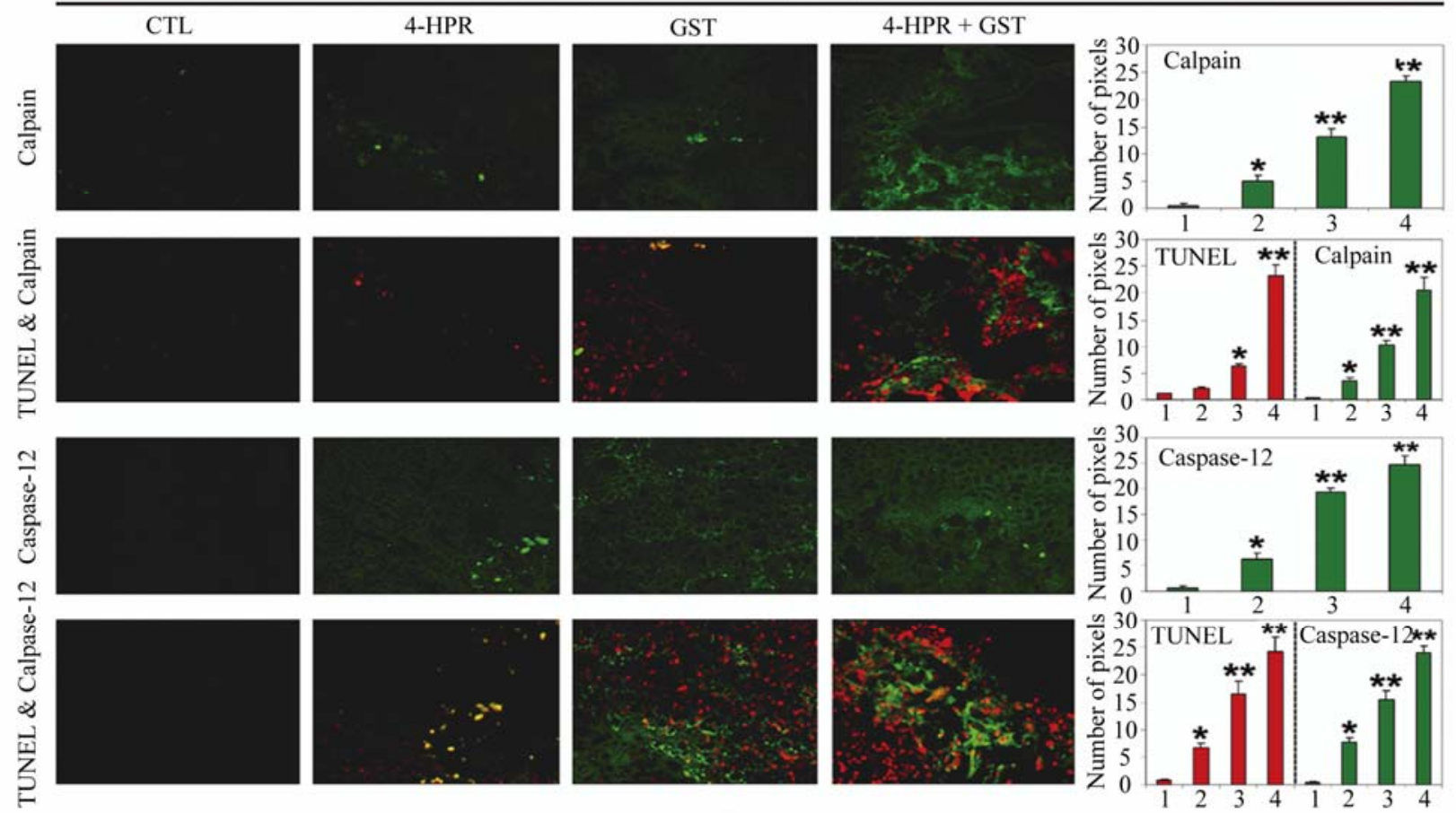

(b)

Figure 7. In situ stainings for examination of upregulation of calpain and caspase-12 in association with DNA fragmentation in the sections of neuroblastoma xenografts. Treatments (8 days): CTL, 4-HPR (20 $\mu \mathrm{g} / \mathrm{kg} / \mathrm{day}), \mathrm{GST}(2 \mathrm{mg} / \mathrm{kg} / \mathrm{day})$, and 4-HPR $(20 \mu \mathrm{g} / \mathrm{kg} / \mathrm{day})+4 \mathrm{~h}$ later GST $(2 \mathrm{mg} / \mathrm{kg} / \mathrm{day})$. (a) The SIF and DIF stainings of the sections of ectopic SH-SY5Y xenografts. (b) The SIF and DIF stainings of the sections of orthotopic SK-N-BE2 xenografts. In the sections (at 200x magnification), calpain or caspase-12 is stained in green and DNA fragmentation (TUNEL labeling) is stained in red. In the bar diagrams, $x$-axis denotes $1=$ CTL, $2=4$-HPR, $3=$ GST, and $4=4$-HPR + GST. 
Ectopic SH-SY5Y xenografts
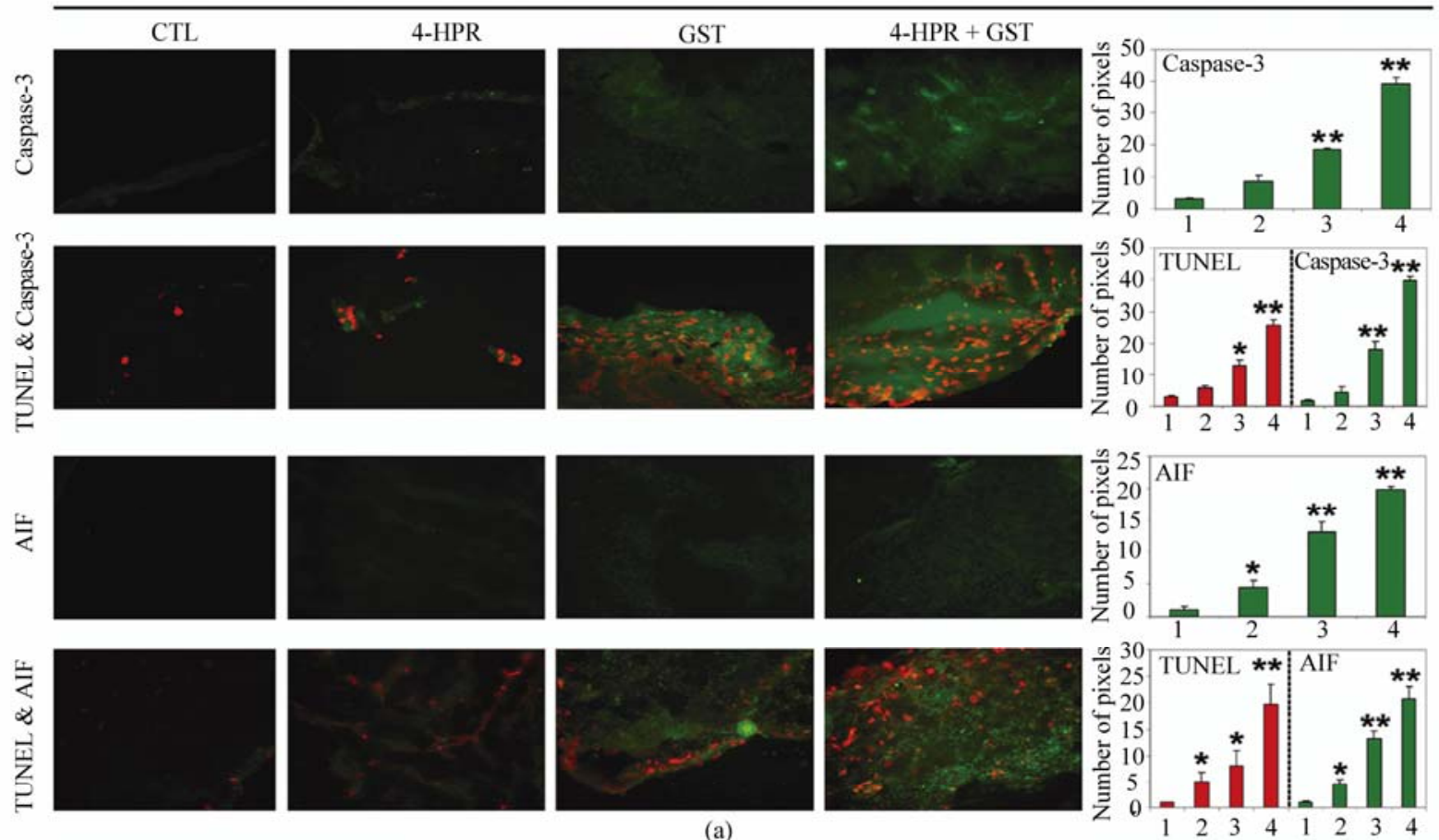

(a)

Orthotopic SK-N-BE2 xenografts

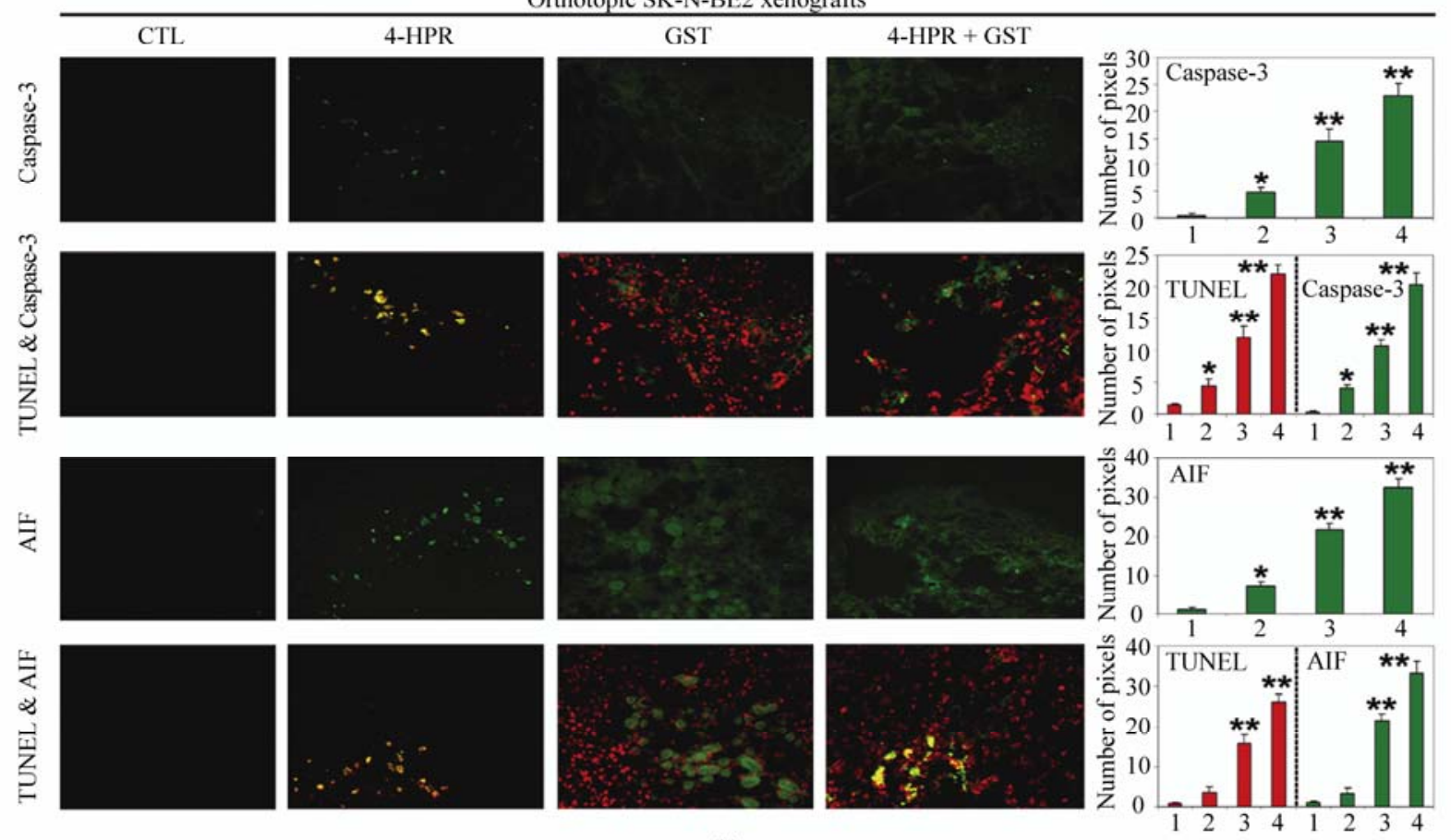

(b)

Figure 8. In situ stainings for examination of upregulation of caspase-3 and AIF in association with DNA fragmentation in the sections of neuroblastoma xenografts. Treatments (8 days): CTL, 4-HPR (20 $\mu \mathrm{g} / \mathrm{kg} / \mathrm{day})$, GST (2 mg/kg/day), and 4-HPR $(20 \mu \mathrm{g} / \mathrm{kg} / \mathrm{day})+4 \mathrm{~h}$ later GST $(2 \mathrm{mg} / \mathrm{kg} / \mathrm{day})$. (a) The SIF and DIF stainings of the sections of ectopic SH-SY5Y xenografts. (b) The SIF and DIF stainings of the sections of orthotopic SK-N-BE2 xenografts. In the sections (at 200x magnification), caspase-3 or AIF is stained in green and DNA fragmentation (TUNEL labeling) is stained in red. In the bar diagrams, $x$-axis denotes $1=$ CTL, $2=4$-HPR, $3=$ GST, and $4=4$-HPR + GST. 
following combination therapy with 4-HPR and 1-threodihydrosphingosine (safingol) in SK-N-MC cells [26]. Similarly, GST induced apoptosis through alterations in Bax and Bcl-2 levels in breast [27] and head and neck squamous cell carcinoma cell lines [28]. Thus, it would be highly plaussible that combination of 4-HPR and GST increased $\mathrm{Bax}: \mathrm{Bcl}-2$ ratio to trigger the mitochondrial release of the pro-apoptotic molecule Smac/Diablo to down regulate the anti-apoptotic BIRC proteins and activate the downstream apoptotic pathways.

Levels of expression of BIRC-2 (cIAP-1) and BIRC-3 (cIAP-2) are often stimulated in cancers and cause suppression of caspase activation for inhibition of apoptosis [29] and can act as oncogenes leading to cell survival, transformation, and resistance to radiation and chemotherapies [30]. Smac/Diablo acts as an indirect activator of caspases by inhibition of the BIRC proteins [21] to facilitate the caspase-dependent pathway of apoptosis following treatment with combination of 4-HPR and GST in ectopic SH-SY5Y xenografts. Treatment with this combination therapy increased activation of the $\mathrm{Ca}^{2+}$-dependent cysteine protease calpain, which could play a significant role in cell death with alternations in expression of the $\mathrm{Bcl}-2$ family members leading to an increase in Bax:Bcl-2 ratio [31] and Bax translocation to mitochondria for release of Smac/Diablo [32]. Calpain can also activate caspase-3 for cytoskeletal brakedown and apoptosis in cancers including neuroblastoma $[12,25]$. Our finding is consistent with previous studies demonstrating that increases in calpain [33] and caspase-3 [34] activation play important role in induction of apoptosis in SH-SY5Y xenografts after treatment with 4-HPR + GST.

Loss of mitochondrial membrane integrity can release AIF to induce caspase-independent apoptosis [35] that we also found following 4-HPR + GST therapy in ectopic SH-SY5Y xenografts. Calpain has been strongly associated with mitochondrial release of AIF and translocation to the nucleus [36] to cause caspase-independent nuclear DNA fragmentation. The increase in caspase-4 activation and activity following 4-HPR + GST combination therapy indicated involvement of ER stress in induction of apoptosis that could be due to 4-HPR [37] or GST [9] monotherapy or due to their combined effects. Recent studies demonstrate that 4-HPR induces the generation of reactive oxygen species (ROS) for mitochondrial damage leading to apoptosis in six neuroblastoma cell lines [38] and also ER stress induces cell death in neuroectodermal tumor cells [39]. Studies in oral squamous cell carcinoma (OSCC) cell line demonstrated that combination of cetuximab and GST caused dose-dependent significant decrease in cell proliferation when compared with either drug alone [40]. Our observations suggested that 4-HPR + GST combination therapy triggered mitochondrial caspase-dependent and caspase-independent pathways and also ER stress for apoptosis in SH-SY5Y xenografts. In line with our observation, a recent investigation reported that combination of bortezomib and 4-HPR increased apoptosis through activation of the ER stress in neuroblastoma cells when compared with either monotherapy [41]. Also, increased survival time in tumor-bearing mice and histological evaluation proved that combination of bortezomib and 4-HPR increased anti-tumor and anti-angiogenic mechanisms [41]. Similarly, combination of cetuximab and GST significantly inhibited tumor growth and caused a substantial delay in tumor growth in animal models of OSCC while no delay in tumor growth was observed using either monotherapy alone [40]. Thus, understanding the complex regulation of cell death pathways through mitochondrial damage or ER stress in response to 4-HPR + GST combination therapy has the potential to reveal novel therapeutic targets in neuroblastoma, as we observed in present preclinical models.

We used the SIF staining to examine a specific protein expression and the DIF staining to examine a specific protein expression in association with DNA fragmentation in course of apoptosis in both neuroblastoma ectopic SH-SY5Y and orthotopic SK-N-BE2 xenografts. Our results indicated significant involvement of both calpain and caspase-12 overexpression in apoptosis in both neuroblastoma xenografts. We also found significant upregulation of caspase-3 and AIF for apoptosis in both neuroblastoma xenografts. Calpain is known to cause ER stress and activation of caspase-12 for apoptosis [42]. Active caspase- 12 is able to directly activate caspase- 9 and caspase- 3 for inducing apoptosis [43,44]. Our observation is correlated with previous studies showing that GST increased intracellular $\mathrm{Ca}^{2+}$ concentration due to release from ER $\mathrm{Ca}^{2+}$ storage to activate the $\mathrm{Ca}^{2+}$-dependent cysteine protease calpain and the ER protease caspase-12 for apoptosis in breast cancer cells [10]. We previously reported that GST caused increase in intracellular free $\mathrm{Ca}^{2+}$ for activation of calpain and caspase- 12 leading to activation of caspase-3 in SH-SY5Y cells for apoptosis [12]. Activation of calpain could cause mitochondrial release of AIF to promote caspase-independent apoptosis.

In conclusion, our investigation showed that 4-HPR + GST worked synergistically for increasing apoptosis in human malignant neuroblastoma SH-SY5Y and SK-N-BE2 cells and induced multiple molecular mechanisms for increasing apoptosis in ectopic SH-SY5Y xenografts as well as in orthotopic SK-N-BE2 xenografts. The results 
from our investigation strongly suggest that combination of 4-HPR and GST should be explored as a promising therapeutic strategy for the treatment of malignant neuroblastoma in humans in the near future.

\section{Acknowledgements}

This investigation was supported in part by the grant R01 NS-57811 from the National Institutes of Health (Bethesda, MD) to S. K. R.

\section{REFERENCES}

[1] S. Y. Sun and R. Lotan, "Retinoids and Their Receptors in Cancer Development and Chemoprevention," Critical Reviews in Oncology Hematology, Vol. 41, No. 1, 2002, pp. 41-55. doi:10.1016/S1040-8428(01)00144-5

[2] A. L. Sabichi, H. Xu, S. Fischer, C. Zou, X. Yang, V. E. Steele, G. J. Kelloff, R. Lotan and J. L. Clifford, "Retinoid Receptor-Dependent and Independent Biological Activities of Novel Fenretinide Analogues and Metabolites," Clinical Cancer Research, Vol. 9, No. 12, 2003, pp. 4606-4613.

[3] N. Hail Jr., H. J. Kim and R. Lotan, "Mechanisms of Fenretinide-Induced Apoptosis," Apoptosis, Vol. 11, No. 10, 2006, pp. 1677-1694. doi:10.1007/s10495-006-9289-3

[4] Q. D. Hewson, P. E. Lovat, M. Corazzari, J. B. Catterall and C. P. Redfern, "The NF- $\kappa$ B Pathway Mediates Fenretinide-Induced Apoptosis in SH-SY5Y Neuroblastoma cells," Apoptosis, Vol. 10, No. 3, 2005, pp. 493-498. doi:10.1007/s10495-005-1878-Z

[5] A. Garaventa, R. Luksch, L. M. S. Piccolo, E. Cavadini, P. G. Montaldo, M. R. Pizzitola, L. Boni, M. Ponzoni, A. Decensi, B. De Bernardi, F. F. Bellani and F. Formelli, "Phase I Trial and Pharmacokinetics of Fenretinide in Children with Neuroblastoma," Clinical Cancer Research, Vol. 9, No. 6, 2003, pp. 2032-2039.

[6] S. Chen, R. N. Fariss, R. K. Kutty, R. Nelson and B. Wiggert, "Fenretinide-Induced Neuronal Differentiation of ARPE-19 Human Retinal Pigment Epithelial Cells is Associated with the Differential Expression of Hsp70, 14-3-3, Pax-6, Tubulin $\beta$-III, NSE, and Bag-1 Proteins," Molecular Vision, Vol. 12, No. 11, 2006, pp. 1355-1363.

[7] E. J. Park and J. M. Pezzuto, "Botanicals in Cancer Chemoprevention," Cancer and Metastasis Reviews, Vol. 21, No. 3-4, 2002, pp. 231-255. doi:10.1023/A:1021254725842

[8] F. H. Sarkar and Y. Li, "The Role of Isoflavones in Cancer Chemoprevention," Frontiers in Bioscience, Vol. 9, No. 1, 2004, pp. 2714-2724. doi:10.2741/1430

[9] T. C. Yeh, P. C. Chiang, T. K. Li, J. L. Hsu, C. J. Lin, S. W. Wang, C. Y. Peng and J. H. Guh, "Genistein Induces Apoptosis in Human Hepatocellular Carcinomas via Interaction of Endoplasmic Reticulum Stress and Mitochondrial Insult," Biochemical Pharmacology, Vol. 73, No. 6, 2007, pp. 782-792. doi:10.1016/j.bcp.2006.11.027
[10] I. N. Sergeev, "Genistein Induces $\mathrm{Ca}^{2+}$-Mediated, Calpain/Caspase-12-Dependent Apoptosis in Breast Cancer Cells," Biochemical and Biophysical Research Communications, Vol. 321, No. 2, 2004, pp. 462-467. doi:10.1016/j.bbrc.2004.06.173

[11] A. Brown, P. Jolly and H. Wei, "Genistein Modulates Neuroblastoma Cell Proliferation and Differentiation through Induction of Apoptosis and Regulation of Tyrosine Kinase Activity and N-myc Expression," Carcinogenesis, Vol. 19, No. 6, 1998, pp. 991-997. doi:10.1093/carcin/19.6.991

[12] A. Das, N. L. Banik and S. K. Ray, "Mechanism of Apoptosis with the Involvement of Calpain and Caspase Cascades in Human Malignant Neuroblastoma SH-SY5Y Cells Exposed to Flavonoids," International Journal of Cancer, Vol. 119, No. 11, 2006, pp. 2575-2585. doi:10.1002/ijc. 22228

[13] G. M. Brodeur, "Neuroblastoma: Biological Insights into a Clinical Enigma," Nature Reviews Cancer, Vol. 3, No. 3, 2003, pp. 203-216. doi:10.1038/nrc1014

[14] S. Irshad, R. B. Pedley, J. Anderson, D. S. Latchman and V. Budhram-Mahadeo, "The Brn-3b Transcription Factor Regulates the Growth, Behavior, and Invasiveness of Human Neuroblastoma Cells in Vitro and in Vivo," The Journal of Biological Chemistry, Vol. 279, No. 20, 2004, pp. 21617-21627. doi:10.1074/jbc.M312506200

[15] J. M. Maris and K. K. Matthay, "Molecular Biology of Neuroblastoma," Journal of Clinical Oncology, Vol. 17, No. 7, 1999, pp. 2264-2279.

[16] R. Torkin, J. F. Lavoie, D. R. Kaplan and H. Yeger, "Induction of Caspase-Dependent, p53-Mediated Apoptosis by Apigenin in Human Neuroblastoma," Molecular Cancer Therapeutics, Vol. 4, No. 1, 2005, pp. 1-11.

[17] S. Karmakar, K. A. Davis, S. R. Choudhury, A. Deeconda, N. L. Banik and S. K. Ray, "Bcl-2 Inhibitor and Apigenin Worked Synergistically in Human Malignant Neuroblastoma Cell Lines and Increased Apoptosis with Activation of Extrinsic and Intrinsic Pathways," Biochemical and Biophysical Research Communications, Vol. 388, No. 4, 2009, pp. 705-710. doi:10.1016/j.bbrc.2009.08.071

[18] J. M. Joseph, N. Gross, N. Lassau, V. Rouffiac, P. Opolon, L. Laudani, K. Auderset, J. F. Geay, A. Mühlethaler-Mottet and G. Vassal, "In Vivo Echographic Evidence of Tumoral Vascularization and Microenvironment Interactions in Metastatic Orthotopic Human Neuroblastoma Xenografts," International Journal of Cancer, Vol. 113, No. 6, 2005, pp. 881-890. doi:10.1002/ijc.20681

[19] S. Karmakar, N. L. Banik, S. J. Patel and S. K. Ray, "Combination of All-Trans Retinoic Acid and Taxol Regressed Glioblastoma T98G Xenografts in Nude Mice," Apoptosis, Vol. 12, No. 11, 2007, pp. 2077-2087. doi:10.1007/s10495-007-0116-2

[20] S. Karmakar, N. L. Banik and S. K. Ray, "Combination of All-Trans Retinoic Acid and Paclitaxel-Induced Differentiation and Apoptosis in Human Glioblastoma U87MG Xenografts in Nude Mice," Cancer, Vol. 112, 
No. 3, 2008, pp. 596-607. doi:10.1002/cncr.23223

[21] C. Du, M. Fang, Y. Li, L. Li and X. Wang, "Smac, a Mitochondrial Protein that Promotes Cytochrome $c$-Dependent Caspase Activation by Eliminating IAP Inhibition," Cell, Vol. 102, No. 1, 2000, pp. 33-42. doi:10.1016/S0092-8674(00)00008-8

[22] K. Beppu, J. Jaboine, M. S. Merchant, C. L. Mackall and C. J. Thiele, "Effect of Imatinib Mesylate on Neuroblastoma Tumorigenesis and Vascular Endothelial Growth Factor Expression," Journal of the National Cancer Institute, Vol. 96, No. 1, 2004, pp. 46-55. doi:10.1093/jnci/djh004

[23] J. L. Armstrong, G. J. Veal, C. P. Redfern and P. E. Lovat, "Role of Noxa in p53-Independent Fenretinide-Induced Apoptosis of Neuroectodermal Tumours," Apoptosis, Vol. 12, No. 3, 2007, pp. 613-622. doi:10.1007/s10495-006-0020-1

[24] M. Gleichmann, G. Buchheim, H. El-Bizri, Y. Yokota, T. Klockgether, S. Kügler, M. Bähr, M. Weller and J. B. Schulz, "Identification of Inhibitor-of-Differentiation 2 (Id2) as a Modulator of Neuronal Apoptosis," Journal of Neurochemistry, Vol. 80, No. 5, 2002, pp. 755-762. doi:10.1046/j.0022-3042.2002.00760.x

[25] S. Karmakar, N. L. Banik, S. J. Patel and S. K. Ray, "Garlic Compounds Induced Calpain and Intrinsic Caspase Cascade for Apoptosis in Human Malignant Neuroblastoma SH-SY5Y Cells," Apoptosis, Vol. 12, No. 4, 2007, pp. 671-684. doi:10.1007/s10495-006-0024-X

[26] S. Batra, C. P. Reynolds and B. J. Maurer, "Fenretinide Cytotoxicity for Ewing's Sarcoma and Primitive Neuroectodermal Tumor Cell Lines Is Decreased by Hypoxia and Synergistically Enhanced by Ceramide Modulators," Cancer Research, Vol. 64, No. 15, 2004, pp. 5415-5424. doi:10.1158/0008-5472.CAN-04-0377

[27] Y. Li, S. Upadhyay, M. Bhuiyan and F. H. Sarkar, "Induction of Apoptosis in Breast Cancer Cells MDA-MB231 by Genistein," Oncogene, Vol. 18, No. 20, 1999, pp. 3166-3172. doi:10.1038/sj.onc. 1202650

[28] S. A. Alhasan, J. F. Ensley and F. H. Sarkar, "Genistein Induced Molecular Changes in a Squamous Cell Carcinoma of the Head and Neck Cell Line," International Journal of Oncology, Vol. 16, No. 2, 2000, pp. 333-338.

[29] C. Y. Wang, M. W. Mayo, R. G. Korneluk, D. V. Goeddel and A. S. Baldwin Jr., "NF- $\kappa$ B Antiapoptosis: Induction of TRAF1 and TRAF2 and c-IAP1 and c-IAP2 to Suppress Caspase-8 Activation," Science, Vol. 281, No. 5383, 1999, pp. 1680-1683. doi:10.1126/science.281.5383.1680

[30] E. C. La Casse, S. Baird, R. G. Korneluk and A. E. MacKenzie, "The Inhibitors of Apoptosis (IAPs) and Their Emerging Role in Cancer," Oncogene, Vol. 17, No. 25, 1998, pp. 3247-3259. doi:10.1038/sj.onc.1202569

[31] A. Büki, D. O. Okonkwo, K. K. Wang and J. T. Povlishock, "Cytochrome $c$ Release and Caspase Activation in Traumatic Axonal Injury," The Journal of Neuroscience, Vol. 20, No. 8, 2000, pp. 2825-2834.
[32] F. Altznauer, S. Conus, A. Cavalli, G. Folkers and H. U. Simon, "Calpain-1 Regulates Bax and Subsequent Smacdependent Caspase-3 Activation in Neutrophil Apoptosis," The Journal of Biological Chemistry, Vol. 279, No. 7, 2004, pp. 5947-5957. doi:10.1074/jbc.M308576200

[33] R. Nath, K. J. Raser, D. Stafford, I. Hajimohammadreza, A. Posner, H. Allen, R. V. Talanian, P. Yuen, R. B. Gilbertsen and K. K. Wang, "Non-Erythroid $\alpha$-Spectrin Breakdown by Calpain and Interleukin $1 \beta$-Converting-Enzyme-Like Protease(s) in Apoptotic Cells: Contributory Roles of Both Protease Families in Neuronal Apoptosis," Biochemical Journal, Vol. 319, No. 3, 1996, pp. 683-690.

[34] K. K. Wang, R. Posmantur, R. Nath, K. McGinnis, M. Whitton, R. V. Talanian, S. B. Glantz and J. S. Morrow, "Simultaneous Degradation of II- and II-Spectrin by Caspase 3 (CPP32) in Apoptotic Cells," The Journal of Biological Chemistry, Vol. 273, No. 35, 1998, pp. 2249022497. doi:10.1074/jbc.273.35.22490

[35] S. P. Cregan, V. L. Dawson and R. S. Slack, "Role of AIF in Caspase-Dependent and Caspase-Independent Cell Death," Oncogene, Vol. 23, No. 16, 2004, pp. 2785-2796. doi:10.1038/sj.onc.1207517

[36] G. Cao, J. Xing, X. Xiao, A. K. Liou, Y. Gao, X. M. Yin, R. S. Clark, S. H. Graham and J. Chen, "Critical Role of Calpain I in Mitochondrial Release of ApoptosisInducing Factor in Ischemic Neuronal Injury," The Journal of Neuroscience, Vol. 27, No. 35, 2007, pp. 9278-9293. doi:10.1523/JNEUROSCI.2826-07.2007

[37] H. Kadara, L. Lacroix, D. Lotan and R. Lotan, "Induction of Endoplasmic Reticulum Stress by the Pro-Apoptotic Retinoid N-(4-Hydroxyphenyl) Retinamide via a Reactive Oxygen Species-Dependent Mechanism in Human Head and Neck Cancer Cells," Cancer Biology \& Therapy, Vol. 6, No. 5, 2007, pp. 705-711. doi:10.4161/cbt.6.5.3963

[38] R. Cuperus, R. Leen, G. A. Tytgat, H. N. Caron and A. B. van Kuilenburg, "Fenretinide Induces Mitochondrial ROS and Inhibits the Mitochondrial Respiratory Chain in Neuroblastoma," Cellular and Molecular Life Sciences, Vol. 67, No. 5, 2010, pp. 807-816.

doi:10.1007/s00018-009-0212-2

[39] J. L. Armstrong, R. Flockhart, G. J. Veal, P. E. Lovat and C. P. Redfern, "Regulation of Endoplasmic Reticulum Stress-Induced Cell Death by ATF4 in Neuroectodermal Tumor Cells," The Journal of Biological Chemistry, Vol. 285, No. 9, 2010, pp. 6091-6100. doi:10.1074/jbc.M109.014092

[40] S. J. Park, M. J. Kim, Y. K. Kim, S. M. Kim, J. Y. Park and H. Myoung, "Combined Cetuximab and Genistein Treatment Shows Additive Anti-Cancer Effect on Oral Squamous Cell Carcinoma," Cancer Letters, Vol. 292, No. 1, 2010, pp. 54-63. doi:10.1016/j.canlet.2009.11.004

[41] G. Pagnan, D. Di Paolo, R, Carosio, F. Pastorino, D. Marimpietri, C. Brignole, A. Pezzolo, M. Loi, L. J. Galietta, F. Piccardi, M. Cilli, B. Nico, D. Ribatti, V. Pistoia and 
M. Ponzoni, "The Combined Therapeutic Effects of Bortezomib and Fenretinide on Neuroblastoma Cells Involve Endoplasmic Reticulum Stress Response," Clinical Cancer Research, Vol. 15, No. 4, 2009, pp. 1199-209. doi:10.1158/1078-0432.CCR-08-2477

[42] S. Muruganandan and A. E. Cribb, "Calpain-Induced Endoplasmic Reticulum Stress and Cell Death Following Cytotoxic Damage to Renal Cells," Toxicological Sciences, Vol. 94, No. 1, 2006, pp. 118-128. doi:10.1093/toxsci/kfl084

[43] R. V. Rao, S. Castro-Obregon, H. Frankowski, M. Schuler, V. Stoka, G. del Rio, D. E. Bredesen and H. M. El- lerby, "Coupling Endoplasmic Reticulum Stress to the Cell Death Program. An Apaf-1-Independent Intrinsic Pathway," Journal of Biological Chemistry, Vol. 277, No. 24, 2002, pp. 21836-21842. doi:10.1074/jbc.M202726200

[44] M. Tiwari, A. Kumar, R. A. Sinha, A. Shrivastava, A. K. Balapure, R. Sharma, V. K. Bajpai, K. Mitra, S. Babu and M. M. Godbole, "Mechanism of 4-HPR-Induced Apoptosis in Glioma Cells: Evidences Suggesting Role of Mitochondrial-Mediated Pathway and Endoplasmic Reticulum Stress," Carcinogenesis, Vol. 27, No. 10, 2006, pp. 2047-2058. doi:10.1093/carcin/bgl051 